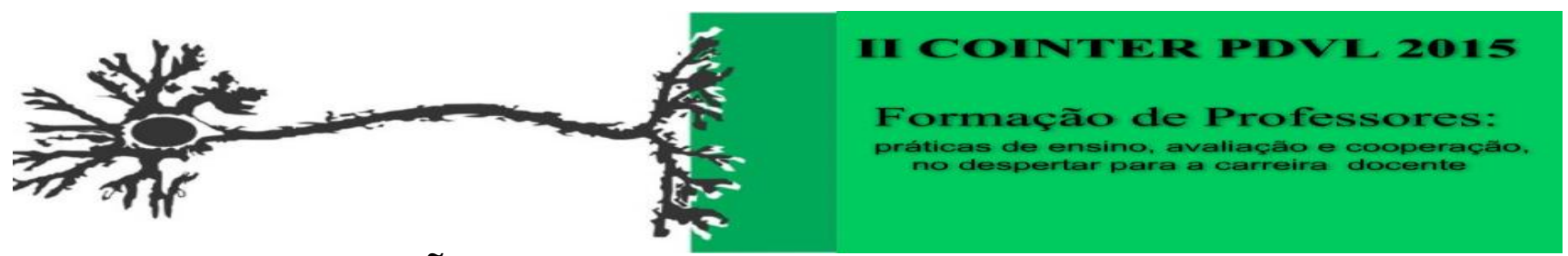

\title{
COMPREENSÕES DOCENTES SOBRE A ROTINA ESCOLAR E O TRABALHO PEDAGÓGICO COM JOVENS INSTITUCIONALIZADAS
}

\author{
Apresentação: Comunicação Oral \\ Isabela Ribeiro Villares Nascimento ${ }^{1}$; Maria de Fátima Silva ${ }^{2}$; Jorge Leandro Ezequiel Farias ${ }^{3}$ José $^{\circ}$ \\ Policarpo Júnior ${ }^{4}$
}

\begin{abstract}
Resumo
Este artigo tem por objetivo apresentar o resultado de pesquisa qualitativa realizada em escola inserida em Unidade de Atendimento Socioeducativo feminina. Nos debruçamos à verificação do funcionamento, da rotina, dos principais desafios apontados pelas educadoras e as suas compreensões sobre a importância da relação educador-educando para as adolescentes. Como resultado, verificamos que fatores como: agressões físicas e verbais, excitação emocional, sono, fome, necessidade de fumar e falta de motivação das discentes para com as atividades educativas, interferem diretamente na rotina e no desenvolvimento do trabalho pedagógico. Tais fatores, associados a tensão e o clima de medo, gerava nas docentes a sensação de impotência. Mas, por outro lado, as docentes demonstraram respeito às discentes e crença na modificação de suas condutas a partir da educação escolar.
\end{abstract}

Palavras-Chave: trabalho pedagógico, práticas docentes, educação.

\section{Introdução}

O presente artigo tem como objetivo apresentar o resultado de pesquisa ${ }^{1}$ qualitativa realizada em uma escola inserida em um Centro de Atendimento Socioeducativo feminino, localizado na cidade do Recife. O estudo foi realizado para fins de conclusão de curso, constitui a primeira parte da investigação e busca elucidar como é desenvolvido o trabalho pedagógico em escola que atende jovens em conflito com a lei. Para compreendermos a dinâmica escolar, nos debruçamos à verificação do funcionamento e rotina da escola, dos principais desafios apontados pelos educadores referentes ao ensino e suas compreensões a respeito da importância do processo educativo e da relação educador-educando para as jovens institucionalizadas.

Para ampliar a nossas possibilidades de análise, localizamos os estudos de Feijó e Assis (2004), Gallo e Williams (2008), Cella e Camargo (2009), Silva e Ristum (2010) e Veronese e Vieira (2003), que tratam da temática e nos forneceram importante descrição sobre a educação de jovens institucionalizados e os principais fatores associados à conduta infracional.

\footnotetext{
Pedagoga, Universidade Federal de Pernambuco, isabelavillares@ yahoo.com.br

Pedagogia, Universidade Federal de Pernambuco, fatima.capi@gmail.com

Geografia, Universidade Federal de Pernambuco, farias426@yahoo.com.br

Professor Dr. do Centro de Educação, Universidade Federal de Pernambuco,jpj@ formacaohumana.org.br
} 
"Basta, eu não quero mais ser desrespeitada, humilhada e espancada"2 : o campo empírico

O campo de pesquisa é uma escola da Rede Estadual de Educação do Recife, inserida em unidade socioeducativa. O funcionamento ocorre nos turnos da manhã e tarde. No turno da manhã há três turmas: 1 (uma) turma de $3^{\circ}$ ano do Ensino Fundamental I e 2 (duas) de $8^{\circ}$ ano do Ensino Fundamental II, ambas da Educação de Jovens e Adultos. O trabalho pedagógico realizado por 9 (nove) docentes, uma coordenadora pedagógica e um gestor tem a finalidade de garantir às adolescentes o acesso à escola e as condições para o exercício da cidadania (PERNAMBUCO, 2013). A turma pesquisada foi a de $3^{\circ}$ ano do Ensino Fundamental I, com 12 adolescentes matriculadas, uma alfabetizada.

$\mathrm{Na}$ observação do cotidiano, identificamos que a instituição funcionava com número superior ao permitido, de 20 a 25 adolescentes. No período de julho a dezembro de 2014, manteve sob regime de internação em média 35 adolescentes com idades entre 14 e 20 anos, entre as quais quatro encontravam-se grávidas. Os atos infracionais com maior percentual de recorrência eram: tráfico de entorpecentes $(37,4 \%)$, roubo e assalto $(25,3 \%)$ e homicídio $(11,9 \%)^{3}$. De acordo com a professora (P1) "quando a casa está cheia fica mais difícil controlar as brigas entre as meninas". As associações ou grupos são formados por afinidade ou poder. No relato da professora (P3), “as mais vulneráveis ou novatas tendem a procurar alguém mais forte e isso gera brigas e ciúmes entre elas, quando isso acontece nós, dependendo do caso, solicitamos a gestão da unidade a transferência". Num dado momento das observações, um dos grupos de meninas recebeu uma das transferidas de outra unidade com a expressão "bem-vinda ao inferno", em coro. Os processos de admissão podem ser desenvolvidos numa forma de iniciação por um dos grupos, e essa expressão, subjetivamente, busca dar ao "novato uma noção clara de sua situação" (GOFFMAN, 2010, p. 27).

O número total de internas varia em decorrência de transferências e liberação por cumprimento da medida socioeducativa. Identificamos que os atos de agressão física e moral entre as jovens foram os principais motivos de transferências, utilizadas também como medida punitiva e de contenção da agressividade no grupo. De acordo com a professora (P2), "às vezes a retirada de uma menina nos traz um sentimento de culpa, uma sensação de que não estamos conseguindo educá-la, realizar bem o nosso trabalho, que não estamos indo bem”. Os estudos de Cella e Camargo (2009) revelam que a culpa e a sensação de fracasso são emoções presentes no cotidiano de socioeducadoras e contribuem para o questionamento sobre o significado do seu trabalho, o que pode levar ao isolamento, sensação de não pertencimento e impotência.

A rotina estabelecida pela equipe pedagógica funcionava em 4 momentos: primeiro as 
meninas eram acolhidas com a oração ${ }^{4}$, depois direcionavam-se às suas salas de aulas, no momento seguinte desfrutavam de um intervalo de 30 min e no restante do dia participam de atividades de artes, como oficina de artesanato, aulas de dança, canto e capoeira. Quando questionada sobre a oração no momento da acolhida, a professora (P2) o caracterizou como "um momento de aproximação a Deus, das dores (sic) de cada uma". Segundo a mesma, “é quando nos sentimos com o coração mais leve para enfrentar todos os problemas que surgem durante o dia". Para a professora (P3) é "como um colo" e "indispensável à harmonia na escola".

A meta educativa da escola é orientada pela política educacional da Secretaria de Educação. Nas falas das professoras a respeito das metas para o ano letivo, ficou evidente considerável preocupação em atingir o objetivo de alfabetizar as adolescentes que estavam no $3^{\circ}$ ano do Ensino Fundamental I (EJA), e garantir a continuidade dos estudos para as demais. Cerca de 11 adolescentes não sabiam ler e escrever, as demais tinham dificuldade de compreensão da leitura. Os percursos educativos das adolescentes foram interrompidos por fatores como: associação ao tráfico de drogas, envolvimento constante em brigas na escola, falta de acompanhamento familiar, abandono do lar e outros. O aprendizado da leitura e escrita, associado a fatores como presença escolar, domínio dos conteúdos curriculares, disciplina, bom rendimento nas avaliações e adequação à rotina da escola (caracterizados como bom comportamento) produziam efeitos positivos no processo de análise para liberação da medida infracional. Para justificar a reinserção da interna à sociedade era verificado o avanço nos aprendizados conceituais e atitudinais salientados.

$\mathrm{O}$ direito à educação pública, gratuita e de qualidade dos adolescentes está prevista na Constituição Federal de 1988 como um direito social (Art. $6^{\circ}$ ), a ser efetivado pelo Estado enquanto dever (At. 208). A Lei de Diretrizes de Bases da Educação de 1996 define a finalidade do processo educativo como meio de desenvolvimento do educando, preparo para o exercício da cidadania e qualificação para o trabalho (Art. $2^{\circ}$ ). O Estatuto da Criança e do Adolescente estabelece que na aplicação de medidas de proteção ao menor, inclusive em casos específicos de privação da liberdade, os investimentos pedagógicos priorizam o fortalecimento dos vínculos familiares e comunitários (Art. 100). De acordo com o aparato legal e políticas destinadas a infância e a juventude, a educação destina-se ao preparo do indivíduo para a cidadania. No entanto, a pesquisa realizada por Rodrigues e Cruz (2010), sobre a relação do adolescente institucionalizado com a escola, aponta que fatores como reprovação, mudança constante de endereço, uso de drogas, ausência dos pais na escola, pobreza e necessidade de trabalhar na infância para contribuir com a renda familiar são fatores que causam desencanto e afastam os adolescentes da escola. Logo, as condições de existência influenciam na evasão, permanência e valorização da educação como meio de acesso aos bens materiais e cultuais. Apesar do aparato legal e das políticas públicas para 
adolescentes em conflito com a lei, a prática educacional institucionalizada tem se revelado ineficaz quanto ao preparo para a cidadania, não obstante os esforços empregados, por que os fatores de vulnerabilidade do menor e sua família estão associados a conduta infracional e reforçam a formação da rota marginal (VERONESE;VIEIRA, 2003).

Nas observações, o ensino e a cumprimento dos objetivos curriculares eram comprometidos por causa da falta interesse e motivação discente, brigas, ausência da família e transferências das adolescentes. Além desses, a atenção doada a resolução dos conflitos entre as jovens atrapalhava a dinâmica do trabalho pedagógico e expunha as professoras as agressões físicas.

A sala de aula é um espaço atravessado por fatores que interferem diretamente na prática das professoras. As jovens, em suas conversas paralelas, expõem o desejo de sair da unidade e isso desvia a atenção no momento da explanação do conteúdo. Na maior parte das aulas observadas, no momento das falas da professora (P1), as alunas escreviam frases nas paredes e nas carteiras sobre suas mães e a vontade de serem livres. É evidente o clima de desconforto pela condição de privação da liberdade. Esses fatores, segundo a docente, fazem com que "tenha sempre que buscar novas estratégias de ensino, que nem sempre dão certo".

A reorganização do trabalho pedagógico é elaborada pelo grupo de docentes e a gestão, quinzenalmente, segundo necessidade de planejamento e revisão dos objetivos educacionais da Rede Estadual de Ensino. De acordo com a professora (P3), “o trabalho em equipe de revisão das ações ajuda na visualização dos pontos a serem corrigidos e os objetivos já alcançados”. No que se refere à meta instituída pela escola, a partir da sua realidade, a mesma professora, que atua como coordenadora pedagógica, diz que "as situações de ensino são organizadas de acordo com os avanços das meninas, mas dependem muito de fatores que afetam diretamente a sala de aula para serem concluídas". De acordo com as observações, a fome e a necessidade de fumar (tabaco) são fatores que interrompem o planejado e "esgotam as intenções de fazer um bom trabalho", disse a professora (P1), que apontou como uma das principais dificuldades para realização do planejado.

$\mathrm{O}$ cigarro era usado como moeda de troca entre as adolescentes. As agentes retiravam o cigarro em caso de envolvimento em brigas ou depredação do patrimônio. A retirada do cigarro, para as meninas, era a punição mais grave, segundo uma das professoras. O cigarro, em geral, era conseguido pelas menores por via de doações de familiares, agentes e até alguns professores. A falta de controle da vontade de fumar gerava excitação e alvoroço nas internas, que muitas vezes saiam da sala de aula para saciar essa necessidade.

Fora da instituição socioeducativa se tinha o poder de decisão sobre o uso do cigarro; dentro, essa decisão era dada à equipe de agentes. O uso era apresentado como uma recompensa, o que muitas vezes gerava a "construção de comportamentos em torno desses privilégios" 
(GOFFMAN, 2010, p. 51). Os comportamentos eram a obediência aos comandos das agentes. Tais comportamentos nem sempre eram refletidos a partir do efeito e razoabilidade de suas ações, mas reproduzidos em meio "aos modos de organização dos castigos e privilégios peculiares à instituição" (Idem).

Quando indagada sobre o que mais dificulta o trabalho docente na instituição, a professora (P2) disse ser a política da unidade socioeducativa, que "às vezes dificulta o trabalho dos professores", pois "as agentes, para resolver problemas disciplinares, retiram as adolescentes de sala sem a permissão da professora ou respeito a aula". A política a que se referiu é a organização e funcionamento do Centro de Atendimento Socioeducativo. Para essa mesma professora, há "uma forma de tratamento que desmonta o que procuramos ensinar sobre respeito". Na acepção de Cella e Camargo (2009), o local destinado a internação não deve se assemelhar a um estabelecimento prisional, mas sim um de aprendizado e desenvolvimento pedagógico. No entanto, mesmo diante dos esforços para construção desse ambiente escolar, a cultura prisional mantinha-se presente e contribuía para a formação de um clima desconfortável, por causa da presença do sentimento de medo, tensão e desconfiança, na escola.

Ressaltamos na relação entre as docentes e discentes alguns traços que consideramos elucidativos, porém, acreditamos que não devemos nos fixar nos mesmos para formar qualquer tipo de prejulgamento de suas práticas. A professora (P1) quase sempre ressaltava aspectos negativos do comportamento das meninas, como, por exemplo, preguiçosas e "respondonas". Outras vezes elogiava algumas delas por sua caligrafia, pela iniciativa de fazer a tarefa de sala. Essa docente trabalha há 29 anos em unidades socioeducativas e se considera cansada. A professora (P2) tinha a prática de conversar com as adolescentes e estimular a fala sobre os problemas que as conduziram à instituição, mas com posicionamentos religiosos que se sobressaiam, muitas vezes, como verdades incontestáveis. A mesma professora utilizava o desenho, a escrita, a pintura e outros métodos como forma de expressão das ideias das adolescentes. A professora (P3) sempre realizava o momento da acolhida com as discentes e professores com oração e leitura de textos religiosos. Em outros momentos repreendia com segurança as ações das adolescentes, na intenção de fazê-las respeitar as regras da escola. Durante as aulas, a professora (P3) elogiava os avanços das meninas e aconselhava sobre o valor da educação para a vida.

Pudemos observar que as docentes, em graus variados, possuem influência sobre o comportamento das meninas. A professora $(\mathrm{P} 2)$, às vezes até de forma exaltada, chamavam-nas à responsabilidade de fazer as tarefas e evitar se envolverem em conflitos na unidade. A professora (P1) buscava encorajar as discentes a praticar a escrita e ressalta, repetidamente, a importância de elas aprenderem a ler e escrever, embora demonstrasse pouco entusiasmo na ação de alfabetizar. A 
professora (P3) estabelecia a roda de diálogos para se aproximar, ouvir e conversar com as adolescentes e demais profissionais sobre os problemas que afetam a rotina. Em um de seus relatos disse que às "meninas falta do mais básico, como roupas, ao essencial, que é a família. Nós, muitas vezes, somos um refúgio do mundo para elas, principalmente para as grávidas”, relatou a professora (P3). A maioria das adolescentes não tinha no registro de nascimento o nome do pai e algumas entravam na unidade sem qualquer documentação, o que dificultava a localização dos pais ou parentes. Essas meninas viveram sua infância em abrigos, disse a professora (P1).

Os fatores apontados como motivadores para a atuação como docentes foram o progresso que as adolescentes apresentam no campo afetivo e intelectual. Os desmotivadores foram a política da instituição socioeducativa, a falta de interesse em aprender de algumas adolescentes e as agressões entre as jovens.

No que diz respeito às discentes, segundo a professora (P2), "há uma descrença na vida muito grande". Quando indagada sobre a forma como a escola lidava com a questão da descrença, respondeu que "infelizmente não é possível fazer muito, pois essas meninas são sem referência, sem afeto, lar, comida. O que podemos fazer é dar carinho, oportunidade de ver que há algo diferente do que sempre viram nas ruas. Isso, todos nós educadores fazemos". Sobre o trabalho desenvolvido na escola e em sala de aula as docentes caracterizam como um desafio constante e a coordenadora revelou ser "difícil, estressante", mas que também "aprende muito com as meninas".

\section{Metodologia}

Quanto aos aspectos metodológicos, foram realizadas observações e entrevistas com 3 (três) docentes. As observações ocorreram no espaço da escola, que ocupa uma ala restrita da instituição. As visitas acumularam um total de 72 horas, distribuídas em 18 encontros de 4 horas cada um. As três primeiras visitas foram para observação geral: coleta de dados em documentos da escola, como o Plano de Trabalho do Coordenador Pedagógico (2014), observação das interações entre os sujeitos, a rotina, funcionamento etc. As demais visitas reorientaram a pesquisa, pois devido à forma como o grupo interage para a resolução dos conflitos internos e a influência significativa de algumas educadoras sobre as jovens, optamos pela ampliação do número de observações e de docentes a serem entrevistadas; de uma ampliamos para três docentes.

Os sujeitos entrevistados foram: P1 - professora atuante em turma de $3^{\circ}$ ano do Ensino Fundamental; P2 - professora de Artes e P3 - professora atuante na Coordenação Pedagógica. A turma observada foi a de $3^{\circ}$ ano do Ensino Fundamental I, da Educação de Jovens e Adultos. 
Consideramos que a presença das três exercia maior influência sobre o grande grupo, composto pelas estudantes (internas), demais professores e agentes socioeducativos. Essa presença nos é relevante para análise das suas compreensões sobre a importância da educação, uma vez que essas docentes permaneciam mais tempo com as discentes. Os dados foram coletados a partir de observações em sala de aula, no atelier de artes, em contatos com a Coordenação Pedagógica, por análise de documentos referentes às atribuições da Coordenação e entrevistas realizadas com as educadoras mencionadas.

\section{Conclusões}

A escola e a meta educativa para jovens em conflito com a lei instauram contato com problemas que, desde muito cedo, afetam a vida de crianças e adolescentes fora da instituição, como: ausência dos genitores e falta de acompanhamento desses no desenvolvimento da criança, uso de drogas lícitas ou ilícitas, ausência de referências positivas nos espaços de socialização, abandono ou perda do interesse escolar, violência doméstica e outros. Essas jovens estão imersas em contextos de exclusão material e cultural que os tornam vulneráveis a delinquência juvenil. Segundo Feijó e Assis (2010) a segregação cultural priva o indivíduo de obter uma escolaridade que o instrumentalize a obter satisfação material e acesso a informações que o habilitem a exercer sua cidadania de forma plena. Nesse sentido, mesmo diante da intenção de despertar as adolescentes institucionalizadas para o valor da escolarização, as formas de exclusão trazem como consequências uma série de fatores difíceis de serem superados pela escola. Decorre disso, muitas vezes, a falta de crença na vida, relatada por uma das professoras em referência às discentes, é fruto da segregação.

Os atos de agressão física e moral entre as jovens apareceram como principais motivos de interferência na dinâmica escolar; decorre desses, a necessidade de fumar, fome, sono e desmotivação para com a assimilação dos conteúdos curriculares. Apesar da frequente necessidade de readequação do planejamento pedagógico, por causa da permanência dos fatores elencados, as docentes demonstraram significativa responsabilidade com o ensino, mesmo diante de falas que acentuam aspectos negativos das adolescentes ou com discursos religiosos inquestionáveis.

As docentes relataram ser difícil o desenvolvimento do trabalho na escola, mas também classificaram como de grande aprendizagem. Ainda assim, às vezes, sentiam-se impotentes quando não conseguiam mediar os conflitos violentos e recorriam a métodos coercitivos, como o deferimento de pedido de transferência de adolescente envolvida em brigas. Essa solicitação era utilizada como último recurso, pois apresentaram como objetivo desconstruir a ideia de prisão, mesmo diante da política de funcionamento e gestão da unidade socioeducativa. 
Os conflitos violentos interferem diretamente na prática do professor, e enfrentá-los torna-se um desafio diário. Uma maneira de enfrentamento desses conflitos, identificada nas observações, era o diálogo, promovidos pelas docentes para reflexão da conduta das adolescentes e da equipe pedagógica. Alguns comportamentos das discentes eram engessados na necessidade de se obter uma avaliação positiva de si para o abrandamento da medida socioeducativa. Porém, segundo avaliação das professoras, "era perceptível a mudança de comportamento a partir da mudança de olhar das meninas". Uma das formas de mudança desse olhar era o momento da acolhida (oração), que as ajudavam na estabilidade de suas emoções, o que refletia na diminuição dos conflitos entre as jovens. As práticas docentes expressavam acentuado compromisso e afetividade para com os relacionamentos entre educadoras e educandas, algo que auxiliava na mediação do clima de medo e desconfiança.

Em nossa concepção, a prática docente, imbuída do compromisso de incluir os sujeitos na relação pedagógica, não se ancorada apenas na transmissão de conteúdos, mas se completa na expressão do reconhecimento da importância do outro na ação de educar. Salienta Röhr (2007) que, "a apropriação existencial de um sentido faz a pessoa agir de acordo com o sentido que adquiriu". Esse autor fala sobre o autoconhecimento e a apropriação de um sentido para a vida. Na escola, devido a sua peculiaridade, acreditamos que a criação de mais de espaços e encontros para o diálogo que visasse o autoconhecimento, garantiria aos indivíduos mais condições de refletir sua atuação com o outro, a forma como projeta sua imagem e a da outra pessoa e os caminhos a serem percorridos para contribuir com a formação humana dos sujeitos sociais, culturais, históricos etc. Essa prática, se compreendida dentro da necessidade de auxiliar o docente, na tomada de decisões a respeito da reorganização do trabalho pedagógico, e o discente, na reorientação da sua conduta, não reduz o fazer educativo a um processo de aquisição de conteúdos empíricos para a socialização, mas o qualifica como âmbito de possibilidades de crescimento do indivíduo.

\section{Referências}

BRASIL. Lei $\mathrm{n}^{\circ}$ 8.069, de 13 de julho de 1990. Dispõe sobre o Estatuto da Criança e do Adolescente e dá outras providências. Brasília. Diário Oficial da União, Brasília, DF, 16 jul. Seção $1,1990$.

BRASIL. Secretaria Especial dos Direitos Humanos. Conselho Nacional dos Direitos da Criança e do Adolescente. Sistema Nacional Socioeducativo - SINASE. Brasília. 2006.

BRASIL. Senado Federal. Constituição da República Federativa do Brasil de 1988. Diário Oficial. 
BRASIL. Senado Federal. Lei de Diretrizes e Bases da Educação Nacional. Lei n 9394/96. Brasília: 1996.

CELLA, S. M.; CAMARGO, D. M. P. Trabalho pedagógico com adolescentes em conflito com a lei: feições da exclusão/inclusão. Educação e Sociedade, Campinas, V. 30, n. 106, p. 281-299, 2009.

FEIJÓ, M. C; ASSIM, S. G. O contexto de exclusão social e de vulnerabilidade de jovens infratores e de suas famílias. Estudos de Psicologia (Natal), v. 9, n. 1, p. 157-166, 2004.

FUNASE, Fundação de atendimento Socioeducativo. Regimento Interno. Recife. 2013.

GALLO, A. E; WILLIAMS, L. C. A. A escola como fator de proteção à conduta infracional de adolescentes. Cadernos de Pesquisa, v. 38, n. 133, 2008.

GOFFMAN, E. Manicômios, prisões e conventos. São Paulo: Perspectiva, 2010.

PASIAN, S. M. A educação de jovens em espaço de restrição da liberdade: fatores de risco associados. Revista Eletrônica de Educação, v. 8, n. 3, p. 226-235, 2014.

PERNAMBUCO. Secretaria de Educação do Estado de. Contrato de Convivência. Recife, 2013.

PERNAMBUCO. Secretaria de Educação do Estado de. Plano de Trabalho do Coordenador Pedagógico. Recife, 2014.

PERNAMBUCO. Secretaria de Educação do Estado de. Projeto Político Pedagógico. Recife, 2013.

RODRIGUES, R. T. F. R.; CRUZ, G. C. Da sala à cela: rotas marginais de adolescentes em situação de conflito com a lei. 33 . Reunião anual da ANPEd, 17 a 20 de outubro - Caxambu/MG, 2010.

ROHR, Ferdinand. Reflexões em torno de um possível objeto epistêmico próprio da Educação. Pró-Posições, vol.18, n. 1(52) - jan./abril. 2007.

SILVA, J. O.; RISTUM, M. A violência escolar no contexto de privação de liberdade. Psicologia: Ciência e Profissão, v.30, n.2, p. 232-247, 2010.

VERONESE, J. R.; VIEIRA, C. E. A educação básica na legislação brasileira. Revista Sequência, n. 47 , p. $99-125,2003$.

i - A pesquisa foi desenvolvida no período de julho a novembro de 2014, para fins de elaboração de trabalho de conclusão de curso.

i - Trecho escrito por uma das adolescentes em um trabalho realizado e exposto na escola no dia 08 de março de 2014, dia Internacional da Mulher. Nas produções expostas havia outras falas referentes a violência contra a mulher, como: "estou cansada de apanhar", "não quero mais ser violentada", "não quero mais ser abandonada" e outras. A violência presente nas ações das adolescentes, dentro e fora da instituição, são manifestações de sofrimento e abandono a que estão submetidas desde a infância, segundo afirmação da Professora (P2).

i - As informações foram retiradas da base de dados estatísticos publicados no site da instituição socioeducativa. Fonte eletrônica: 〈http://www.funase.pe.gov.br/estatistica.php> 
i - A oração fazia culto a apenas uma vertente religiosa, o que contraria o princípio da liberdade de culto ou a laicidade das instituições públicas, previsto na Constituição Federal de 1988, em seu Art. $5^{\circ}$. Mas, segundo justificativa para a manutenção dessa prática na escola, a professora (P3), disse que o objetivo era o de "apaziguar os estados de excitação emocional", o que garantia o clima de tranquilidade para o desenvolvimento do trabalho pedagógico. 